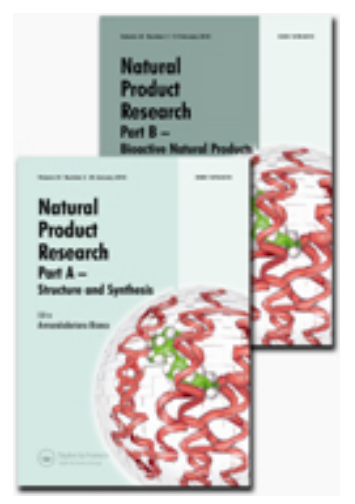

\title{
GC-MS analysis and biological activity of hydroalcholic extracts and essential oil of Rhus typhina L. wood (Anacardiaceae) in comparison with leaves and fruits.
}

\begin{tabular}{|c|c|}
\hline Journal: & Natural Product Research \\
\hline Manuscript ID & Draft \\
\hline Manuscript Type: & Short Communication \\
\hline $\begin{array}{r}\text { Date Submitted by the } \\
\text { Author: }\end{array}$ & $\mathrm{n} / \mathrm{a}$ \\
\hline Complete List of Authors: & $\begin{array}{l}\text { Arlandini, Emanuele; University of Milan, Department of Environmental } \\
\text { Science and Policy } \\
\text { Gelmini, Fabrizio; University of Milan, Department of Environmental } \\
\text { Science and Policy } \\
\text { Testa, Cristian; Functional Point S.r.I., } \\
\text { Angioletti, Stefania; Functional Point S.r.I., } \\
\text { Beretta, Giangiacomo; University of Milan, Department of Environmental } \\
\text { Science and Policy }\end{array}$ \\
\hline Keywords: & $\begin{array}{l}\text { Rhus typhina L., Essential oil, hydroalcoholic extract, wood, antioxidant, } \\
\text { antibacterial, GC-MS }\end{array}$ \\
\hline
\end{tabular}

\section{SCHOLARONE $^{\text {m }}$ Manuscripts}






URL: http://mc.manuscriptcentral.com/gnpl Email: GNPL-peerreview@journals.tandf.co.uk 


\section{GC-MS analysis and biological activity of hydroalcholic extracts and essentiasl}

2 oils of Rhus typhina L. wood (Anacardiaceae) in comparison with leaves and

3 fruits.

4

5 Emanuele Arlandini ${ }^{1 \neq}$, Fabrizio Gelmini ${ }^{1 \neq}$, Cristian Testa $^{2}$, Stefania Angioletti ${ }^{2}$, Giangiacomo

6 Beretta $^{1 *}$

7

$8{ }^{1}$ Department of Environmental Science and Policy, Università degli Studi di Milano, via 9 Mangiagalli 25, 20133, Milan, Italy

10 2Functional Point S.r.l., Laboratorio di Microbiologia e Virologia, via Ghislandi 61/B, 24125, 11 Bergamo, Italy

14 These authors equally contributed to the work

15 *Corresponding author: E-mail address: giangiacomo.beretta@unimi.it

17 Keywords: Rhus typhina L., EO, hydroalcoholic extract, wood, antioxidant activity, 18 antimicrobial activity, GC-MS 


\section{Abstract}

Hydroalcoholic extract and essential oils (EO) of branches, leaves and fruits of Rhus typhina L., were characterized by GC-MS. The hydroalcoholic extracts (branches $68.30 \mathrm{mg} / \mathrm{g}$, leaves 35.82 $\mathrm{mg} / \mathrm{g}$ and fruits $257.76 \mathrm{mg} / \mathrm{g}$ ), showed different compositions dominated by gallic acid (33.46\%) in branches, its precursor 1-cyclohexane-3,4,5-hydroxy-carboxylic acid (20.55\%) in leaves and malic acid $(89.15 \%)$ in fruits.

EO yields were $210 \mu \mathrm{g} / \mathrm{g}$ for branches with $\delta$-cadinene as main component (22.00\%), followed by fruits with $132 \mu \mathrm{g} / \mathrm{g}$ ( $\beta$-pinene main component 32.2\%) and leaves with phenylacetaldehyde as major component $(54 \mu \mathrm{g} / \mathrm{g}, 40.13 \%)$.

Total phenolic content (TPC) was highest in branches hydroalcoholic extracts $(5.87 \mu \mathrm{g} \mathrm{GAE} / \mathrm{mL})$, while the maximal TPC of EO was observed in leaves $(17.71 \mu \mathrm{g} \mathrm{GAE} / \mathrm{mL})$.

The highest value of radical scavenging activity (DPPH test) was detected in both leaves hydroalcoholic extracts and EO.

The branches EO in vitro antimicrobial activity was strong against $C$. albicans $(\varnothing>35 \mathrm{~mm}$, MIC $0.16 \mu \mathrm{g} / \mathrm{mL}$ ) and negligible against $E$. coli. The leaves and fruits EO showed strong activity against C. albicans and intermediate activity against Escherichia coli.

\section{Introduction}

Sumac is the name of the genus Rhus that includes more than 250 individual species of plants in the family Anacardiaceae (USDA, 2007 Germplasm Resources Information Network), growing mostly in wild areas in temperate and tropical regions.

R. typhina, staghorn sumac (Chinese sumac) is a shrub found in North America and Europe; it develops spontaneously in marginal areas of Northern Italy and is extensively cultivated in Northwest China to obtain its red fruits. They are used for the production of a traditional beverage named 'sumacade', sumac iced tea or Rhus juice (Peterson, 1977; Kossah et al., 2010). However also other parts of this plant are considered a source of a variety of nutritionally and medicinally useful chemical components such as essential aminoacids, unsaturated fatty acids, vitamins and organic acids (Wang and Zhu, 2017). Concerning the plant wood, only the biological activities of extracts from the species $R$. verniciflua were investigated (Kitts and Lim, 2001), while the work of Islambekov et al. (1994) on R. glabra and R. typhina stems extracts and of Antal et al. (2010) on $R$. cotinus L. wood determined the structure of some of its components.

EO are the object of continuous studies for their antibacteric, antimicrobial, antiviral, antimicotic and antioxidant properties (Beretta et al., 2011; Gelmini et al., 2015) but to the best of our knowledge no information on hydroalcoholic extracts of branches of $R$. typhina and on EO of 

59

60 61 62 63 64 65 66

branches and fruits is available. Hence, the aim of the present study was to determine the composition and bioactivity (antioxidant and antimicrobial activity) of hydroalcoholic extracts and EO of its branches with a GC-MS based metabolomic approach and to compare them with those of leaves and fruits.

\section{Results and discussion}

\subsection{Chemical composition of hydroalcoholic extracts of differeht vegetative organs of $R$.} thyphina

\subsubsection{Hydroalcoholic extracts of branches}

The chromatographic profile of branches hydroalcoholic extracts is shown in Fig. S1A with 40 peaks of identified substances, accounting for $96.07 \%$ of the total area (with RT $>8$ min to exclude peaks generated by the derivatizing agent). Compound identifications (Table S1) revealed four main classes: (I) phenolic acids such as gallic acid $\mathrm{C}_{7} \mathrm{H}_{6} \mathrm{O}_{5}(33.78 \%$, RT=31.06 min, main peak 61), (II) sugars and polyalcohols of which arabitol $\mathrm{C}_{5} \mathrm{H}_{12} \mathrm{O}_{5}(8.26 \%, \mathrm{RT}=24.97 \mathrm{~min})$ was the main peak 27, (III) flavonoids, identified in the range $\mathrm{RT}=47-51 \mathrm{~min}$ and recognized all as catechins (total relative amount 8.4\%), as previously found in the aqueous extract of leaves of $R$. coriaria (Regazzoni et al. 2013) and (IV) other constituents of relevant nutraceutical interest as lactic acid $(1.93 \%, \mathrm{RT}=8.48 \mathrm{~min})$.

\subsubsection{Hydroalcoholic extract of leaves}

The chemical composition of leaves hydroalcoholic extracts (RT range 13-60 min, Table S1, Fig S1B) indicated the presence of (I) phenolic acids dominated by 3,4,5-trihydroxy-1-cyclohexanecarboxylic acid $\left(\mathrm{C}_{7} \mathrm{H}_{12} \mathrm{O}_{5}, 20.55 \%, \mathrm{RT}=27.52 \mathrm{~min}\right.$, peak 41), (II) sugars and polyalcohols (29.54\%) and (III) fatty acids and their derivatives detected mainly in the range RT=43- 48 min (total amount $28.54 \%$ ).

\subsubsection{Hydroalcoholic extract of fruits}

The fruits hydroalcohlic extract (Fig. S1C) exhibited very strong quantitative and qualitative differences compared to those of branches and leaves (Table S1). Its composition was largely dominated by malic acid $(89.15 \%, \mathrm{RT}=18.93 \mathrm{~min}$, peak 20$)$, citric acid $(\mathrm{RT}=27.64 \mathrm{~min}, 1.95 \%$, peak 42 ) and gallic acid, $1.73 \%$, peak 61. 


\subsection{Chemical composition of EO of different vegetative organs of R. typhina.}

\subsubsection{Branches EO}

The GC-MS profile of branches EO is shown in Fig. S2A and Table S2. The main compounds detected in the 25-33 min RT range were essentially non oxygenated sesquiterpenes $(76.52 \%$ of the total peak area) and $\delta$-cadinene $(22.07 \%, \mathrm{RT}=31.49 \mathrm{~min}$, peak 113$), \gamma$-cadinene $(9.91 \%, \mathrm{RT}$ $=31.22 \mathrm{~min}$, peak 112), $\gamma$-muurolene (8.91\%, RT=29.65 min, peak 99), aromandendrene (5.96\%, peak 94). Oxygenated sesquiterpenoids (amounting to 6.50\%) appeared at RT $>33$ min: among them there is $\tau$-muurolol (1.94\%, peak 140$)$.

\subsubsection{Leaves EO}

The phytochemical composition of leaves EO were in good accordance with those of Bestmann et al. (1988) from both the qualitative and quantitative $(0.005 \% \mathrm{w} / \mathrm{w})$ point of view. The chemical profile of Fig. 2B appeared completely different from that of branches, with oxygenated derivatives amounting to $86.42 \%$ and with aldehydes accounting for $60.96 \%$ of the total peaks area (Table S2). Phenylacetaldehyde (40.13\%, RT=11.11 min, peak 27), a fragrance and flavour agent with pheromone properties (Youlian et al., 2009) was the major peak with other main pheromone-aldehydes furfural $(5.54 \%, \mathrm{RT}=4.28 \mathrm{~min})$ and 2 -hexenal $(5.22 \%, \mathrm{RT}=4.66 \mathrm{~min}) . \mathrm{In}$ the 3-20 min RT range a set of oxygenated monoterpenoids appeared (19.40\%), while at 20 $<\mathrm{RT}<37$ min sesquiterpenes and sesquiterpenoids were detected in minor quantity (totally $8.75 \%$ ).

\subsubsection{Fruits EO}

The chemical composition of fruits EO was characterized by a high content of non oxygenated derivatives (89.52\%) as shown in Table S2. In Fig. S2C the most abundant compounds were four monoterpenes enclosed in the 5-11 min RT range: $\beta$-pinene $(32.26 \%, \mathrm{RT}=8.28 \mathrm{~min}$, peak 16$), \alpha$ pinene $(14.95 \%, \mathrm{RT}=6.77 \mathrm{~min}$, peak 11), $\beta$-cis-O-cimene $(11.42 \%, \mathrm{RT}=9.47 \mathrm{~min}$, peak 21$)$ and D-limonene $(8.01 \%, \mathrm{RT}=10.32 \mathrm{~min}$, peak 23$)$. A second group of compounds in the 25-32 min RT range consists of sesquiterpenes and accounts for $21.79 \%$ of the total chromatogram area. The main components were $\gamma$ - cadinene $(2.53 \%, \mathrm{RT}=31.16 \mathrm{~min}$, peak 112$), \delta$-cadinene $(6.82 \%$, $\mathrm{RT}=31.37 \mathrm{~min}$ peak 113$)$ and $\gamma$-muurolene $(2.10 \%, \mathrm{RT}=29.66 \mathrm{~min}$, peak 99). Little amounts of compounds with 8,11,13-abietatriene skeleton are also detected: they are responsible for in vitro anti inflammatory activity $v s$ leukotriene B4 formation (Pferschy-Wenzig et al. 2008).

\subsection{Antiradical activity and TPC of hydroalcoholic extracts of R. thyphina}




\subsubsection{Antiradical activity (DPPH test)}

123

124

125

126

127

128

129

130

131

132

133

134

135

136

137

138

139

140

141

142

143

144

145

146

147

148

149

150

151

152

153

154

The DPPH $\mathrm{IC}_{50}$ of branches hydroalcoholic extract was $2.41 \pm 0.08 \mu \mathrm{g}_{\text {ext }} / \mathrm{mL}$, value intermediate between those of leaves $\left(1.11 \pm 0.03 \mu \mathrm{g}_{\text {ext }} / \mathrm{mL}\right)$ and fruits $\left(3.80 \pm 0.12 \mu \mathrm{g}_{\text {ext }} / \mathrm{mL}\right)$. These results were comparable to $\mathrm{IC}_{50}$ reported by Šavikin et al. (2009) who investigated the antiradical activities of $R$. cotinus methanol extracts of leaves and fruits, whose values are respectively $2.6 \pm 0.4 \mu \mathrm{g}_{\text {ext }} / \mathrm{mL}$ and 3.8 $\pm 0.5 \mu \mathrm{g}_{\text {ext }} / \mathrm{mL}$. Simić et al. (2008) determined $\mathrm{SC}_{50}=1.7 \mu \mathrm{g}_{\text {ext }} / \mathrm{mL}$ (ethyl acetate) in the same fraction of dried young shoots. To the best of our knowledge, the antiradical activity of the hydroalcoholic extracts of $R$. typhina branches is reported for the first time in this study.

\subsubsection{Total phenol content Fast Blue BB test (TPC-BB)}

Branches hydroalcoholic extract showed a TPC-BBcontent of $5.87 \pm 0.19 \mathrm{mg}_{\mathrm{GAE}} / \mathrm{g}$, a value higher than that of fruits and leaves extracts $\left(1.70 \pm 0.05 \mathrm{mg}_{\mathrm{GAE}} / \mathrm{g}\right.$ and $1.22 \pm 0.06 \mathrm{mg}_{\mathrm{GAE}} / \mathrm{g}$ respectively). These results are in good agreement with the GC-MS quantitative determination of GAE of hydroalcoholic extracts of branches $(6.81 \pm 0.13 \% \mathrm{w} / \mathrm{w})$, fruits $(1.91 \pm 0.06 \% \mathrm{w} / \mathrm{w})$ and leaves $(0.77 \pm 0.04 \% \mathrm{w} / \mathrm{w})$ (Pearson's product-moment correlation coefficient $\mathrm{R}=0.996, \mathrm{p}<0.05)$.

\subsubsection{Total Phenol Content Folin- Ciocolteau method (TPC-FC)}

According to the TPC-BB results, the TPC-FC of $R$. thyphina branches hydroalcoholic extract was higher than that of leaves and fruits $\left(86.00 \mathrm{mg}_{\mathrm{GAE}} / \mathrm{g}\right.$ vs. $34.26 \mathrm{mg}_{\mathrm{GAE}} / \mathrm{g}$ and $6.22 \mathrm{mg}_{\mathrm{GAE}} / \mathrm{g}$, respectively). The differences of these data in comparison to those reported in literature can be attributed to different factors such as plant genetics, growing conditions, harvesting time and method of extraction and quantification (Itidel et al., 2013).

\subsection{Antiradical activity, TPC and antimicrobial activity of EO of R. thyphina}

\subsubsection{EO antiradical activity}

R. typhina leaves and fruits EO showed greater DPPH scavenging capacity compared to that of branches, as indicated by their respective $\mathrm{IC}_{50}$ values of $2.29 \pm 0.10 \mu \mathrm{L} / \mathrm{mL}$ (leaves), $2.54 \pm 0.06$ $\mu \mathrm{L} / \mathrm{mL}$ (fruits) and $5.80 \pm 0.18 \mu \mathrm{L} / \mathrm{mL}$ (branches).

\subsubsection{EO TPC-BB test}

The EO from leaves showed the highest TPC value, amounting to $17.71 \pm 0.82 \mathrm{mg} \mathrm{GAE}_{\mathrm{G}} / \mathrm{mL}_{\mathrm{EO}}$, followed by that of fruits $\left(10.75 \pm 0.45 \mathrm{mg}_{\mathrm{GAE}} / \mathrm{mL}_{\mathrm{EO}}\right)$ and that of branches $(4.72 \pm 0.22$ 
$\left.155 \mathrm{mg}_{\mathrm{GAE}} / \mathrm{mL}_{\mathrm{EO}}\right)$. In EO a good correlation between TPC values and DPPH scavenging activity 156 observed $(\mathrm{R}=0.877 ; \mathrm{P}<0.05)$, suggests that the reducing components are those responsible also 157 for the EO antiradical activity.

\subsubsection{EO antimicrobial activity}

160 The antimicrobial activity of $R$. typhina EO is reported in the present study for the first time (Table 161 1), being reported in literature only data of antimicrobial activity of $R$. cotinus EO (Milošević et 162 al., 2008). All tested EO (branches, leaves and fruits) showed good in vitro microbial inhibition 163 against $C$. albicans (inhibition zone $22.6<\mathrm{d}<35 \mathrm{~mm}$ vs. $S$. montana EO positive control, MIC 0.02 $164 \mathrm{mg} / \mathrm{mL}$ ). Furthermore, EO from leaves and fruits, but not from branches (inhibition zone $0<\mathrm{d}<17.5$ $165 \mathrm{~mm}, \mathrm{MIC}=0.64 \mathrm{mg} / \mathrm{mL}$ ) were active against E. coli ATCC (inibition zone $17.6<\mathrm{d}<22.5 \mathrm{~mm}$, $166 \mathrm{MIC}=0.064 \mathrm{mg} / \mathrm{mL})$.

167 168 169

\section{Conclusions}

In this study, the extensive fingerprinting and characterization of Italian (Northern Italy) $R$. thyphina L. branches hydroalcoholic extract and EO were reported for the first time, and the results compared with those of its leaves and fruits.

The analyses were performed using a GC-MS methodology that allowed for the single-run, simultaneous detection of several classes of analytes, from oligosaccharides to flavonoids, organic acids, glycerides, highlighting huge compositional differences among the plant vegetative organs. Branches hydroalcohlic extracts of $R$. typhina showed the highest content of gallic acid and the major value of TPC, while leaves extract was characterized mainly by sugars, fatty acids and their derivatives, and by a lower antioxidant activity. The fruits extract was strongly dominated by organic bicarboxylic acids (malic acid89.15\%) and showed a TPC similar to that of leaves.

Among the great number of identified structures of nutraceutical interest, the high content of gallic acid in branches may be exploited in pharmaceutical industry as antioxidant agent while malic acid in the hydroalcoholic extract of fruits may be suitable for the confectionary industry (i.e. biscuits, candy and fruit-based preparations) as savoury agent (tartness), as stabilizer and as preservative ingredient. The presence of bi- and tri-carboxylic acids belonging to the Krebs cycle (succinic, fumaric, citric, isocitric acids) can explain its use for the preparation of tonic beverages with health promoting activity.

Significant differences were observed in the chemical composition of EO of branches in respect of that of leaves and fruits. The former is dominated by cyclic sesquiterpenes and low TPC while that of leaves EO by aldehydes with strong antiradical/antioxidant activity. Fruits EO most 
189 abundant compounds are monoterpenes ( $\beta$-pinene $32.2 \%)$ accompanied by sesquiterpenes with 190 low TPC.

191 Tests of antimicrobial activity on EO of all aerial parts of this medicinal plant found that they are 192 endowed with strong antimicrobial activity against the infections of the saprophytic fungus $C$. 193 albicans while only leaves and fruits have satisfying activity against the Gram negative bacteria 194 E. coli.

195

196 Aknowledgements

197 We thank Mr. C. Goggi, Mrs. L. Goggi (Isola S. Antonio, AL) and Mrs. A. Trecate (Lomello, PV) 198 for access to the plant material.

\section{Funding}

201 This research did not receive any specific grant from funding agencies in the public, commercial, 202 or not-for-profit sectors.

203

204

\section{Declaration}

205

The autors declaire no conflict of interest

206

207

\section{References}

208

209

210

Antal DS, Schwaiger S, Ellmerer-Müller EP, Stuppner H. 2010. Cotinus coggygria wood: novel flavanone dimer and development of an HPLC/UV/MS method for the simultaneous determination of fourteen phenolic constituents. Planta Med. 76:1765-1772.

211

212

Bauer A, Kirby WM, Sherris JC, Turk M. 1966. Antibiotic susceptibility testing by a standardized single disk method. Am. J. Cli Pathol. 45: 493-496.

214

Beretta G, Granata P, Ferrero M, Orioli M, Maffei Facino R. 2005.Standardization of antioxidant

216 properties of honey by a combination of spectrophotometric/fluorimetric assays and 217 chemometrics. Anal.Chim Acta. 533: 185-191.

218 Beretta G, Artali R, Maffei Facino R, Gelmini F. 2011. An analytical and theoretical approach for 219 the profiling of the antioxidant activity of EO: The case of Rosmarinus officinalis L. J. Pharm. 220 Biomed. Analysis. 55: 1255-1264. 
222 Bestmann H-J, Classen B, Kobold U, Vostrowsky O, Klingauf F, Stein U. 1988. Steam volatile 223 constituents from leaves of Rhus typhina. Phytochemistry. 27: 85-90.

224

225

Cos P, Vlietinck A J, Vanden Berghe D, Maes L. 2006. Anti-infective potential of natural products: 226 How to develop a stronger in vitro "proof-of-concept". J. Ethnopharmacol. 106: 290-302 227

Gelmini F, Squillace P, Testa C, Sparacino AC, Angioletti S, Beretta G. 2015. GC-MS characterization and biological activity of essential oils from different vegetative organs of Plectranthus barbatus and Plectranthus caninus cultivated in north Italy. Nat. Prod. Res. 29: 993998.

232

Hudzicki J. 2009. Kirby-Bauer Disk Diffusion Susceptibility Test Protocol. ASMS Microbe 234 Library.AmericanSocietyforMicrobiology.http://www.microbelibrary.org/component/resource/la boratory-test/3189-kirby-bauer-disk-diffusion-susceptibility-test-protocol.

Islambekov SY, Mavlyanov SM, Kamaev FG, Ismailov AI. 1994. Phenolic Compounds of Sumac. Chem. Nat. Comp. 30: 37-39.

Itidel C, Chokri M, Mohamed B, Yosr Z. 2013, Antioxidant activity, total phenol content and flavonoid content variation among Tunisian natural populations of Rhus tripartita (Ucria) Grande and Rhus pentaphylla Desf. Ind. Crops Prod. 51:171-177.

Kitts DD, Lim KT. 2001. Antitumorigenic and cytotoxic properties of an ethanol extract derived from Rhus verniciflua Stokes (RVS). J. Toxicol. Enviro Health. PartA. 64: 357-371.

Kossah R, Nsabimana C, Zhao J, Zhang H, Chen W. 2010. Optimization of extraction of polyphenols from Syrian Sumac (Rhus coriaria L.) and Chinese Sumac (Rhus typhina L.) fruits. 250

Medina MB. 2011. Simple and rapid method for the analysis of phenolic compounds in beverages and grai J. Agric. Food Chem. 59: 1565-1571. 
254 Milošević T, Nićiforović N, Mihailović M, Solujić S, Vucović 2008.Chemical composition 255 andantimicrobial activity of the essential oils of flowers, leaves and stems of Cotinus coggygria. 256 Planta Medica,74:PI 23.

257

258 Peterson LA. 1977. Edible wild plants. Houghton Mifflin Co., New York. 259

260 Pferschy-Wenzig EM, Kunert O, Presser A, Bauer R. 2008. In vitro anti-inflammatory activity of 261 larch (Larix decidua L.) sawdust. J. Agric. Food Chem. 56: 11688-11693.

262

263

264

265

266

267

268

269

270

271

272

273

274

275

276

277

278

279

280

281

282

283

284

285

Regazzoni L, Arlandini E, Garzon D, Santagati NA, Beretta G, Maffei Facino R. 2013. A rapid profiling of gallotannins and flavonoids of the aqueous extract of Rhus coriaria L. by flow injection analysis with high resolution mass spectrometry with data base searching. J.Pharm. Biomed. Analysis. 72: 202-207.

Šavikin K, Zdunić G, Janković T, Stanojković T, Juranić Z, Menković 2009.In vitro cytotoxic and antioxidative activity of Cornus mas and Cotinus Coggygria.Nat. Prod. Res. 23:1731-1739.

Simić M, Vučićević D, Milenković M, Kovačević 2008.Antioxidant and anti-inflammatory activity of Cotinus Coggygria extracts. Planta Med.74: PA63.

USDA 2007. Germplasm Resources Information Network, Beltsville, MD, USA: United States Department of Agriculture, Agricultural Research Service. http://www.ars-grigov/npgs/aboutgrihtmL

Wang S, Zhu F. 2017. Chemical composition and biological activity of staghorn sumac (Rhus typhina). Food Chemistry, 237: 431- 443.

Youlian S, Yang G, Yougjun, 2009. The synergism of plant volatile compounds and sex pheromones of the tobacco cutworm moth.(Lepidoptera Noctuidae). Acta Entomologica Sinica.52:1290-1297. 
286 Table 1. Antimicrobial activity of $R$. typhina EO determined by disk diffusion assay $(+: 0<\mathrm{d}<17.5$

$287 \mathrm{~mm}(1) ;++: 17.6<\mathrm{d}<22.5 \mathrm{~mm} ;+++: 22.6<\mathrm{d}<35 \mathrm{~mm})$ and by microdilution assay $\left(\mathrm{mg}_{\mathrm{EO}} / \mathrm{mL}\right)$.

288 Positive control: Satureja montana EO. d: inhibition area diameter. d.: not detectable.

\begin{tabular}{|l|c|c|c|c|c|c|c|c|}
\hline & \multicolumn{4}{|c|}{ Disk diffusion assay } & \multicolumn{3}{c|}{ Microdilution assay } \\
\hline & Branches & Leaves & Fruits & S. montana & Branches & Leaves & Fruits & S. montana \\
\hline C. albicans ATCC & +++ & +++ & +++ & +++ & 0.16 & 0.08 & 0.08 & 0.02 \\
\hline E. coli ATCC & + & ++ & ++ & ++ & d. & 0.64 & 0.64 & 0.02 \\
\hline
\end{tabular}




\section{EXPERIMENTAL}

2

3

4 5

6 7

8

9 10

\section{GC-MS analysis and biological activity of hydroalcholic extracts and $\mathrm{EO}$ of} Rhus typhina L. wood (Anacardiaceae) in comparison with leaves and fruits.

Emanuele Arlandini ${ }^{1 \ddagger}$, Fabrizio Gelmini ${ }^{1 \ddagger}$, Cristian Testa $^{2}$, Stefania Angioletti ${ }^{2}$, Giangiacomo Beretta $^{1 *}$

${ }^{1}$ Department of Environmental Science and Policy, Università degli Studi di Milano, via Mangiagalli 25, 20133, Milan, Italy

${ }^{2}$ Functional Point S.r.l., Laboratorio di Microbiologia e Virologia, via Ghislandi 61/B, 24125, Bergamo, Italy

\section{Materials and methods}

\section{Plant material}

Branches, leaves and fruits of R. typhina were collected by E. Arlandini in different periods of the year in Northern Italy (Piedmont and Lombardy regions) in the following localities: Isola S. Antonio (Alessandria) lat. $45^{\circ} 02^{\prime} 0^{\prime \prime} \mathrm{N}$; long. $8^{\circ} 51^{\prime} 0^{\prime \prime}$ E, elevation: $76 \mathrm{~m}$ a.s.l.; Sale (Alessandria)

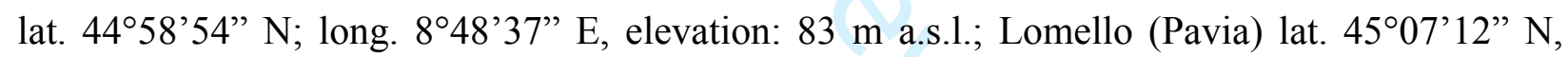
long. 8०47’46” E, elevation: 93 m a.s.1.

\section{Chemicals}

All the following reagents and solvents used were of analytical grade: gallic acid; 2,2-diphenyl1-picrylhydrazyl (DPPH); N,O-bis[trimethylsilyltrifluoroacetamide] (BSTFA); Fast Blue BB; dichloromethane; formic acid; methanol; ethanol; ethylacetate; acetonitrile; pyridine, acetic acid, sodium hydroxide; sodium acetate-tri-hydrate (Sigma-Aldrich, Milan, Italy). Folin-Ciocalteu reagent was purchased from Fluka (Switzerland). Ultra-pure water for reagents preparation was produced using a Milli-Q System (Millipore, Milan, Italy).

\section{Moisture Determination}

The moisture of the plant material was determined in triplicate independent determinations on 35 $\mathrm{g}$ of each specimen in a thermostated oven (Nüve FN-500, Turkey) at $105^{\circ} \mathrm{C}$ until constant weight. The moisture \% content was $10.47 \pm 0.7 \%$ for branches, $56.85 \pm 1.5 \%$ for leaves and $41.98 \pm 0.9 \%$ for fruits.

\section{Hydroalcholic extraction and derivatization}


The hydroalcoholic extraction of branches, leaves and fruits was accomplished on $5.0 \mathrm{~g}$ of powdered material in $100 \mathrm{~mL}$ of $\mathrm{EtOH} / \mathrm{H}_{2} \mathrm{O}=45: 55$ under stirring for 24 hours at room temperature. After filtration, the solvent was evaporated under reduced pressure and $5.0 \mathrm{mg}$ of each dry extract were submitted to derivatization with $140 \mu \mathrm{L}$ of BSTFA, $60 \mu \mathrm{L}$ of pyridine and $200 \mu \mathrm{L}$ of ethyl acetate at $70^{\circ} \mathrm{C}$ for 3 hours. The mixtures were then diluted 1:10 with ethyl acetate and $1.0 \mu \mathrm{L}$ injected into the GC-MS apparatus.

\section{EO extraction}

EOs were obtained by steam distillation for three hours of three aliquots of powdered branches, each of about $124 \mathrm{~g}$ (379.00 g total amount), of six aliquots of powdered leaves of about $123 \mathrm{~g}$ (738.75 g total weight) and seven aliquots o powdered fruits each of about $145 \mathrm{~g}$ (1012.50 g total weight). The hydrodistillation apparatus had a boiler flask of $1000 \mathrm{~mL}$ filled with $800 \mathrm{~mL}$ of water; the length of the column containing the extractable material was $40 \mathrm{~cm}$. The hydrolats resulting from each operation (around $60 \mathrm{~mL}$ ) were extracted with $40 \mathrm{~mL}$ of dichloromethane (three times) in an extraction funnel, the organic fractions were pooled and the solvent evaporated under reduced pressure. The EOs- obtained were diluted (1:1000) in ethyl acetate and $1.0 \mu \mathrm{L}$ of these solutions analysed by GC-MS.

\section{GC-MS}

GC-MS analyses were performed using a Bruker Scion SQ instrument (Bruker Daltonics, Macerata, Italy), equipped with a Varian Factor Four capillary column (VF-5 MS, 30 m; 0.25 $\mathrm{mm}$ i.d., film thickness $0.25 \mu \mathrm{m}$ ) coupled with a single quadrupole (SQ) detector. For the hydroalcoholic extracts, the oven temperature was initially set at $60^{\circ} \mathrm{C}$ (hold time $3 \mathrm{~min}$ ), with a gradient from 60 to $120^{\circ} \mathrm{C}\left(8.0^{\circ} \mathrm{C} / \mathrm{min}\right.$, hold $\left.1 \mathrm{~min}\right), 120-280^{\circ} \mathrm{C}\left(4^{\circ} \mathrm{C} / \mathrm{min}\right.$, hold $\left.1.5 \mathrm{~min}\right), 280^{\circ} \mathrm{C}$ $330^{\circ} \mathrm{C}\left(10^{\circ} \mathrm{C} / \mathrm{min}\right.$, hold $\left.2 \mathrm{~min}\right)$. Total run time was $60 \mathrm{~min}$. For EO analyses the temperature gradient was setted according to Gelmini et al., 2015. Injector temperature $250^{\circ} \mathrm{C}$, hold 20 min. Column flow $1.00 \mathrm{~mL} / \mathrm{min}$. Carrier gas helium 5.5; ionization energy $70 \mathrm{eV}$. The split/splitless ratio was set to $1: 30$ after $45 \mathrm{~s}$. Peaks were identified by matching their mass spectra with those of the commercial library NIST mass spectral database (vers. 2.0, 2011) and with those of owned commercial standards. The percentage compositions of the constituents were obtained by normalization of the peak areas.

\section{Antioxidant activity}

\section{Antiradical activity (DPPH test)}


Radical scavenging activity was determined with the DPPH test according to Beretta et al. (2011). Briefly, a final test solution of $3.0 \mathrm{~mL}$ was obtained by adding $0.5 \mathrm{~mL}$ of DPPH in ethanol $(500 \mu \mathrm{M})$ and $0.1 \mathrm{~mL}$ of ethanol containing different quantities of hydroalcoholic extracts to a mixture formed by $1 \mathrm{~mL}$ of acetate buffer and $1.4 \mathrm{~mL}$ of ethanol. The solutions were shaken and than incubated at $25{ }^{\circ} \mathrm{C}$ in the dark for $90 \mathrm{~min}$. The absorbance of unreacted DPPH was read against a sample blank at $\lambda=517 \mathrm{~nm}$ (Varian Cary 50 Bio spectrophotometer). The scavenging activity was reported as $\mathrm{IC}_{50}$ expressed as $\mu \mathrm{g}$ of hydroalcoholic extract $/ \mathrm{mL}$ of final solution $\left(\mu \mathrm{g}_{\mathrm{ext}} / \mathrm{mL}\right)$ or as $\mu \mathrm{L}$ of $\mathrm{EO} / \mathrm{mL}$ of final solution, required to quench the $\mathrm{DPPH}$ by $50 \%$.

\section{Total phenol content (Fast Blue BB test, TPC-BB)}

TPC was determined using the method reported by Medina (2011), with minor modifications. This assay was based on the reaction of 4-amino-2,5diethoxybenzanilide diazotated zinc double salt with phenols to give colored azo-complexes. The test was done adding $0.1 \mathrm{~mL}$ of Fast Blue BB reagent $(0.1 \% \mathrm{w} / \mathrm{v}$ in methanol) and $0.1 \mathrm{~mL}$ of $5 \% \mathrm{NaOH}$ to a methanol sample solution (1.0 $\mathrm{mg} / \mathrm{mL}$ ). After keeping the solutions in the dark at room temperature for $90 \mathrm{~min}$, the absorbances were read at $\lambda=420 \mathrm{~nm}$. TPC values were calculated by comparison with a calibration curve built using methanol solution of gallic acid at different concentrations $(0-500 \mu \mathrm{g} / \mathrm{mL}) ; y=$ $121522610470,35 \mathrm{x}+3682836246,23 ; \mathrm{R}^{2}=0.9952$.

The GC-MS quantitation was obtained by comparison of the peaks area with that of a calibration curve of silanized gallic acid $\left(\mathrm{y}=1,291 \mathrm{E}+11 \mathrm{x}, \mathrm{R}^{2}=0.989\right)$.

Results were expressed as $\mathrm{mg}$ of gallic acid equivalents/mL of $\mathrm{EO}\left(\mathrm{mg}_{\mathrm{GAE}} / \mathrm{mL}_{\mathrm{EO}}\right)$ or $\mathrm{mg}$ of gallic acid equivalents/g of plant dry material $\left(\mathrm{mg}_{\mathrm{GAE}} / \mathrm{g}\right)$.

\section{Total content of phenol/reducing substances (Folin Ciocoltea test, TPC-FC)}

The total content of reducing substances was determined according to the Folin Ciocolteau method with minor modifications (Beretta et al., 2005, 2011). The hydroalcoholic extracts (50 $\mathrm{mg}$ ) of branches, leaves and fruits of $R$. typhina were dissolved in $1.0 \mathrm{ml}$ of $\mathrm{EtOH} / \mathrm{H}_{2} \mathrm{O} 45: 55$ $\mathrm{vol} / \mathrm{vol}$ and sonicated at maximal power for 2 minutes. $5.0 \mu \mathrm{l}$ of each solution was diluted to 1.0 ml with the Folin-Ciocolteau reagent diluted 1:10 with MilliQ water. The solutions were vortexed for $2 \mathrm{~min}$ and then incubated for $20 \mathrm{~min}$ in the dark at room temperature. The spectrophotometric absorbances were measured at $\lambda=750 \mathrm{~nm}$. All determinations were done in triplicate. The results were expressed as $\mathrm{mg}$ of gallic acid equivalents/g of plant dry material 
$101\left(\mathrm{mg}_{\mathrm{GAE}} / \mathrm{g}\right)$. The GAE was calculated by comparison with a calibration curve plotted with a 102 diluted stock solution $(1 \mathrm{mg} / \mathrm{mL})$ of gallic acid in $\mathrm{EtOH} / \mathrm{H}_{2} \mathrm{O}=45 / 55$.

\section{Antimicrobial activity}

105 The EO antimicrobial activity was determined by disk diffusion test using a series of Kirby106 Bauer antibiogram tests (Microbiologics Inc. USA) as previously reported (Bauer et al.1966, 107 Hudzicki et al. 2009). Briefly, yeast isolates (C. albicans) grew in CHROMAgar and E. coli in 108 McConkey agar without salts. Microorganisms were incubated overnight at $37{ }^{\circ} \mathrm{C}$ under 109 controlled atmosphere. Inocula were prepared diluting the overnight cultures in saline solution to $1101.0 \times 10^{8} \mathrm{CFU} / \mathrm{mL}$. Petri dishes then were inoculated with $1.0 \mathrm{~mL}$ of this suspension. EO $(13 \mu \mathrm{L})$ 111 were added to $13 \mathrm{~mm}$ diameter sterile blank filter disk and placed on the culture medium surface. 112 The agar plates were incubated at $37^{\circ} \mathrm{C}$ for $18-24 \mathrm{~h}$ (E. coli) or $18-48 \mathrm{~h}$ (C. albicans). After 113 incubation, the diameter (d) of the inhibition zones were measured $(\mathrm{mm})$. Results were expressed 114 as follows: resistant (R); $0<\mathrm{d}<17.5 \mathrm{~mm}(1) ; 17.6<\mathrm{d}<22.5 \mathrm{~mm},(2) ; 22.6<\mathrm{d}<35 \mathrm{~mm}$ (3). An 115 authentic EO from Satureja montana was used as positive control.

116 MICs were determined by the broth microdilution method using 96-well microplates modified 117 according to recommendations for the assessment of the antimicrobial potential of natural 118 products (Cos et al., 2006). Serial dilutions $(100 \mu \mathrm{L})$ of each extract were distributed into the 119 plate and diluted in the Muller Hilton Broth making concentrations ranging from 0.02 to $1205.12 \mu \mathrm{g} / \mathrm{mL}$. Thereafter, the plates were inoculated with the respective microorganism suspension 121 to make a final density $5 \times 10^{5} \mathrm{CFU} / \mathrm{mL}$ for bacteria and $1.5 \times 10^{3} \mathrm{CFU} / \mathrm{mL}$ for yeast, 122 respectively. Plates were then incubated at $37^{\circ} \mathrm{C}$ for $24 \mathrm{~h}$ ( $48 \mathrm{~h}$ for C. albicans). Microorganism 123 growth was measured in terms of turbidity recorded at $405 \mathrm{~nm}$.

124 The MIC was expressed as the lowest concentration that showed $\geq 80 \%$ inhibition of microbial 125 growth compared to an extract-free growth control. 
127 Table S1. GC-MS analysis of R. typhina branches, leaves and fruits hydroalcoholic extracts.

\begin{tabular}{|c|c|c|c|c|c|c|}
\hline \multirow{2}{*}{$\begin{array}{c}\text { Peak } \\
\#\end{array}$} & \multirow{2}{*}{$\begin{array}{c}\text { RT } \\
\text { (min) }\end{array}$} & \multirow[t]{2}{*}{ KI } & \multirow[t]{2}{*}{ Substance } & \multicolumn{3}{|c|}{ Relative content (\%) } \\
\hline & & & & Branches & Leaves & Fruits \\
\hline 1 & 5.26 & - & No match & - & - & 0.06 \\
\hline 2 & 5.659 & - & No Match & - & - & 0.11 \\
\hline 3 & 6.168 & 686 & Ethylbis(TMS)amine & - & 0.56 & 0.19 \\
\hline 4 & 6.283 & - & No Match & - & - & 0.02 \\
\hline 5 & 6.335 & - & No Match & - & - & 0.01 \\
\hline 6 & 6.464 & - & Bis(TMS)carbodiimide & - & - & 0.07 \\
\hline 7 & 6.638 & n.a. & Bis(TMS)carbonate & - & - & 0.17 \\
\hline 8 & 7.749 & - & No Match & - & - & 0.05 \\
\hline 9 & 8.082 & 824 & Propyleneglicol,bis-TMS & 0.21 & - & - \\
\hline 10 & 8.495 & 915 & Lactic acid, bis-TMS & 1.93 & - & 0.15 \\
\hline 11 & 12.995 & 1273 & Phosphoric acid, tris(TMS) ester & - & - & 1.01 \\
\hline 12 & 13.039 & 1108 & Glycerol, tris(TMS) ether & 4.07 & 2.06 & - \\
\hline 13 & 13.727 & 1252 & Proline, di-TMS & - & - & 0.04 \\
\hline 14 & 14.005 & 1178 & Maleic acid, diTMS & - & - & 0.09 \\
\hline 15 & 14.283 & 1170 & Succinic acid, di-TMS & - & - & 0.08 \\
\hline 16 & 14.499 & 1199 & Glyceric acid, tri-TMS & - & - & 0.03 \\
\hline 17 & 15.171 & 1178 & Fumaric acid, di-TMS & - & - & 0.85 \\
\hline 18 & 17.358 & 1332 & DL-Malic acid, bis(TMS) ester & - & - & 0.09 \\
\hline 19 & 17.776 & 1317 & D-Erythronic acid $\gamma$-lactone, bis(TMS) ether & - & - & 0.28 \\
\hline 20 & 18.932 & 1390 & Malic acid,tris-TMS & 0.26 & - & 89.15 \\
\hline 21 & 19.287 & 1491 & L-Threitol,tetrakis (TMS)ether & 0.19 & - & - \\
\hline
\end{tabular}




\begin{tabular}{|c|c|c|c|c|c|c|}
\hline 22 & 20.768 & 1518 & 2,3,4-Trihydroxybutyric acid, tetra-TMS & - & 0.16 & - \\
\hline 23 & 20.77 & - & No match & 0.06 & - & - \\
\hline 24 & 23.06 & 1651 & Lyxose, tetra-(TMS)-ether & - & - & 0.01 \\
\hline 25 & 24.334 & 1746 & Ribitol, 5TMS & 0.72 & - & 0.05 \\
\hline 26 & 24.604 & 1326 & d-Erythrotetrofuranose,tris-O-(TMS) & 1.01 & - & - \\
\hline 27 & 24.976 & 1746 & Arabitol,pentakis(TMS)ether & 8.26 & - & - \\
\hline 28 & 25.459 & - & No Match & - & 0.04 & - \\
\hline 29 & 25.888 & 1446 & 2-Deoxy-1,3,4-tris-O-(TMS)pentopyranose & - & 0.16 & 0.03 \\
\hline 30 & 25.892 & - & No Match & 0.17 & & \\
\hline 31 & 26.03 & - & No Match & - & 0.04 & 0.02 \\
\hline 32 & 26.485 & 2029 & $\begin{array}{l}\text { D-(-)-Tagatofuranose, pentakis(TMS) ether } \\
\text { (isomer 2) }\end{array}$ & - & 0.12 & - \\
\hline 33 & 26.495 & - & No Match & 0.23 & - & - \\
\hline 34 & 26.592 & - & No Match & 0.14 & - & - \\
\hline 35 & 26.643 & - & No Match & - & 0.13 & - \\
\hline 36 & 26.647 & 1928 & $\begin{array}{l}\text { Methyl } \\
\text { (TMS)hexopyranoside }\end{array}$ & - & - & 0.03 \\
\hline 37 & 27.147 & 2049 & $\begin{array}{l}\text { D-(-)-Tagatofuranose, pentakis(TMS) ether } \\
\text { (isomer 1) }\end{array}$ & - & 4.53 & - \\
\hline 38 & 27.153 & 1882 & $\begin{array}{l}\text { Glucofuranoside, methyl 2,3,5,6-tetrakis-O- } \\
\text { (TMS) }\end{array}$ & 0.64 & - & 0.25 \\
\hline 39 & 27.167 & 2029 & Sorbofuranose,pentakis(TMS)ether & 4.00 & - & - \\
\hline 40 & 27.361 & 2049 & $\begin{array}{l}\text { D-(-)-Fructopyranose, pentakis(TMS) ether } \\
\text { (isomer 2) }\end{array}$ & 4.01 & 9.89 & 0.50 \\
\hline 41 & 27.516 & 1904 & $\begin{array}{l}\text { 3,4,5-Tris(TMS)-1-cyclohexene-1-carboxylic } \\
\text { acid, TMS ester }\end{array}$ & 3.20 & 20.55 & 0.25 \\
\hline 42 & 27.641 & 1944 & Citric acid, tetra-TMS & - & - & 1.95 \\
\hline 43 & 27.739 & 1900 & Isocitric acid, tetra-TMS & - & - & 0.11 \\
\hline 44 & 27.74 & 1928 & Glycoside, $\alpha$-methyl-tertrakis-O-(TMS)- & 0.20 & 0.12 & - \\
\hline 45 & 28.246 & 1843 & 1,5-Anhydro-D-sorbitol, tetrakis(TMS) ether & 6.42 & 2.93 & 0.32 \\
\hline
\end{tabular}




\begin{tabular}{|c|c|c|c|c|c|c|}
\hline 46 & 28.492 & 2126 & $\begin{array}{l}\text { Isocitric acid lactone, bis(tert- } \\
\text { butyldimethylsilyl) ester }\end{array}$ & 0.78 & 5.10 & - \\
\hline 47 & 28.676 & 1788 & TMS myristate & 0.22 & 2.00 & - \\
\hline 48 & 28.878 & - & No Match & - & 1.67 & 0.34 \\
\hline 49 & 28.906 & 1928 & $\begin{array}{l}\text { Mannopyranoside,methyl 2,3,4,6-tetrakis-O- } \\
\text { TMS }\end{array}$ & 0.81 & - & - \\
\hline 50 & 29.349 & 1970 & Mannopyranose, pentakis(TMS) ether & 0.59 & 2.35 & - \\
\hline 51 & 29.538 & 1981 & Gulonic acid, 1,4-lactone,(4TMS) & 0.09 & - & - \\
\hline 52 & 29.35 & 1692 & D-Xylopyranose, 1,2,3,4-tetrakis-O-(TMS)- & - & - & 0.08 \\
\hline 53 & 29.61 & 1970 & Talopyranose, pentakis(TMS) ether & 0.43 & 0.60 & 0.03 \\
\hline 54 & 29.818 & 1577 & Levoglucosan, tris(TMS)- & 4.10 & 1.26 & 0.10 \\
\hline 55 & 30.295 & 1735 & $\begin{array}{l}\text { 2-Deoxy-arabino-hexonic acid, 1,4-lactone, tris- } \\
\text { O-TMS }\end{array}$ & - & - & 0.02 \\
\hline 56 & 30.156 & 2173 & $\begin{array}{l}\text { D-Galactose,2,3,4,5,6-pentakis-O-TMS-O- } \\
\text { methyloxyme }\end{array}$ & 0.51 & & \\
\hline 57 & 30.307 & - & No Match & 1.81 & & \\
\hline 58 & 30.358 & - & No Match & - & 0.29 & - \\
\hline 59 & 30.456 & - & No Match & - & 0.10 & - \\
\hline 60 & 30.605 & 2053 & $\begin{array}{l}\text { 3,4,5-Trihydroxybenzoic acid ethyl ester, tris } \\
\text { (O-TMS)- }\end{array}$ & 7.61 & 1.36 & 0.51 \\
\hline 61 & 31.06 & 2063 & Gallic acid, tetraTMS & 33.78 & 4.29 & 1.73 \\
\hline 62 & 31.628 & 2194 & Inositol, 1,2,3,4,5,6-hexakis-O-(TMS)-,scyllo- & 0.17 & 4.69 & 0.08 \\
\hline 63 & 31.838 & - & No Match & 0.12 & & \\
\hline 64 & 32.097 & 1991 & D-Allofuranose, pentakis(TMS) ether & - & 0.71 & - \\
\hline 65 & 33.411 & n.a. & Palmitic acid TMS ester & 0.74 & & \\
\hline 66 & 34.835 & 1618 & 2-Deoxy-erythro-pentonic acid, tetrakis-TMS & - & 1.02 & 0.01 \\
\hline 67 & 33.913 & 2194 & Myoinositol TMS & - & 0.08 & - \\
\hline 68 & 34.835 & 1.618 & 2-Deoxy-erythro-pentonic acid, tetrakis-TMS & & 1.02 & 0.01 \\
\hline 69 & 35.406 & - & No Match & - & - & 0.06 \\
\hline 70 & 35.507 & - & No Match & - & - & 0.11 \\
\hline
\end{tabular}




\begin{tabular}{|c|c|c|c|c|c|c|}
\hline 71 & 36.493 & - & No Match & 0.08 & & \\
\hline 72 & 37.166 & 2194 & Oleic acid,TMSester & 0.18 & & \\
\hline 73 & 37.767 & 2186 & Stearic acid, TMS ester & - & 0.62 & - \\
\hline 74 & 40.793 & 2382 & $\begin{array}{l}\text { Myristic acid, 2,3-bis(trimethylsiloxy)propyl } \\
\text { ester }\end{array}$ & - & 0.04 & - \\
\hline 75 & 43.883 & 2581 & 2-Monopalmitoylglycerol TMS ether & 0.13 & 1.50 & 0.02 \\
\hline 76 & 44.017 & 2461 & 4-[(TMS)oxy]butyl palmitate & 0.19 & 8.75 & - \\
\hline 77 & 44.476 & 2581 & 1-Monopalmitin TMS ether & 0.41 & 4.82 & 0.21 \\
\hline 78 & 44.779 & - & No Match & 0.27 & & \\
\hline 79 & 46.549 & - & No Match & 0.17 & & \\
\hline 80 & 46.735 & - & No Match & 0.11 & & \\
\hline 81 & 47.157 & - & No Match & 0.24 & - & - \\
\hline 82 & 47.363 & 2780 & 2-Monostearin TMS ether & 0.13 & 2.81 & 0.02 \\
\hline 83 & 47.631 & - & No Match & - & 6.52 & - \\
\hline 84 & 47.914 & 2780 & Stearic acid, 2,3-bis(trimethylsiloxy)propyl ester & - & 7.85 & 014 \\
\hline 85 & 47.959 & 3227 & Catechine,penta-TMS-ether,(2R-trans) & 1.59 & - & - \\
\hline 86 & 48.415 & - & No Match & 0.08 & - & - \\
\hline 87 & 48.529 & 3227 & Catechine,penta-TMS-ether,(2R-cis) & 2.19 & - & - \\
\hline 88 & 50.103 & 2861 & Catechine & 3.55 & - & - \\
\hline 89 & 50.279 & 2861 & Catechine & 0.70 & - & - \\
\hline 90 & 50.422 & n.a. & $\begin{array}{l}\text { TMSether,methyl ester of p-Hydroxymandelic } \\
\text { acid }\end{array}$ & 0.83 & - & - \\
\hline 91 & 50.983 & 2861 & Catechine & 0.37 & & \\
\hline 92 & 51.782 & - & No Match & - & 0.05 & - \\
\hline 93 & 51.806 & - & No Match & 0.05 & - & - \\
\hline 94 & 51.957 & - & No Match & - & - & 0.14 \\
\hline 95 & 52.305 & 3323 & Aucubin, hexakis(TMS) ether & - & - & 0.03 \\
\hline 96 & 53.059 & - & No Match & - & - & 0.06 \\
\hline 97 & 53.51 & - & No Match & 0.22 & & \\
\hline 98 & 53.93 & 2397 & Anthraquinone, 1,2-dihydroxy, bis-TMS & 0.15 & 0.10 & 0.03 \\
\hline
\end{tabular}




\begin{tabular}{|c|c|c|l|c|c|c|}
\hline 99 & 57.407 & 2417 & Arachidonic acid TMS ester & 0.70 & - & - \\
\hline 100 & 58.515 & - & No match & - & 0.10 & - \\
\hline
\end{tabular}

130 Table S2. GC-MS analysis of $R$. typhina branches, leaves and fruits EOs.

\begin{tabular}{|c|c|c|c|c|c|c|}
\hline \multirow{2}{*}{ Peak \# } & \multirow{2}{*}{$\begin{array}{c}\mathrm{RT} \\
\text { (min) }\end{array}$} & \multirow{2}{*}{$\begin{array}{l}\text { Kovats } \\
\text { Index }\end{array}$} & \multirow{2}{*}{ Substance } & \multicolumn{3}{|c|}{ Relative content (\%) } \\
\hline & & & & Branches & Leaves & Fruits \\
\hline 1 & 3.314 & 790 & Acetylacetone & 0.06 & - & - \\
\hline 2 & 3.559 & 806 & Hexanal & 0.18 & 0.74 & - \\
\hline 3 & 4.007 & 732 & Amylene dichloride & 0.03 & - & - \\
\hline 4 & 4.220 & 976 & Maleic anhydride & - & 0.20 & - \\
\hline 5 & 4.272 & 831 & Furfural & 0.29 & 5.54 & 1.84 \\
\hline 6 & 4.664 & 814 & 2-Hexenal & - & 5.22 & - \\
\hline 7 & 4.715 & - & No Match & 0.16 & - & - \\
\hline 8 & 4.960 & 860 & n-Hexanol & 0.08 & - & - \\
\hline 9 & 5.236 & - & No Match & 0.03 & - & - \\
\hline 10 & 6.203 & 856 & Methional & - & 0.30 & - \\
\hline 11 & 6.769 & 948 & $\alpha$-Pinene & 0.19 & 0.68 & 14.95 \\
\hline 12 & 7.338 & 943 & Camphene & - & - & 0.20 \\
\hline 13 & 7.831 & 913 & 2-Heptenal & - & - & 0.07 \\
\hline 14 & 8.069 & 920 & Furfural, 5-methyl- & - & 1.16 & - \\
\hline 15 & 8.143 & 948 & 3-Carene & & - & 0.42 \\
\hline 16 & 8.276 & 943 & $\beta$-Pinene & 0.19 & - & 32.26 \\
\hline 17 & 8.428 & 969 & 1-Octen-3-ol & 0.18 & - & - \\
\hline 18 & 8.600 & 938 & Sulcatone & 0.69 & 0.59 & - \\
\hline 19 & 8.737 & 958 & $\beta$-Myrcene & $2-$ & - & 0.28 \\
\hline 20 & 9.073 & - & No Match & 0.06 & - & - \\
\hline 21 & 9.479 & 976 & $\beta$-cis-Ocimene & - & - & 11.42 \\
\hline 22 & 10.162 & 1042 & p-Cymene & 0.04 & - & 0.09 \\
\hline 23 & 10.30 & 1018 & Limonene & 0.36 & - & 8.01 \\
\hline 24 & 10.397 & 1212 & 2-Decenal & - & 0.33 & - \\
\hline 25 & 10.398 & 1059 & Eucalyptol & 0.17 & - & - \\
\hline 26 & 10.884 & - & No Match & 0.07 & 0.76 & - \\
\hline 27 & 11.117 & 1081 & Phenylacetaldehyde & 0.90 & 40.13 & - \\
\hline 28 & 11.517 & 998 & $\gamma$-Terpinene & 0.01 & - & 0.14 \\
\hline 29 & 12.060 & 1164 & cis-Linalool oxide & 0.07 & 2.29 & 0.27 \\
\hline 30 & 12.714 & 1052 & Terpinolene & - & - & 1.29 \\
\hline 31 & 12.761 & 1164 & trans-Linalool oxide & 0.10 & 1.46 & - \\
\hline 32 & 13.35 & 1082 & $\beta$-Linalool & 0.62 & 2.12 & 0.19 \\
\hline 33 & 13.578 & 1072 & Hotrienol & - & 3.63 & - \\
\hline 34 & 13.628 & 1104 & Nonanal & 0.18 & - & 0.38 \\
\hline 35 & 13.829 & - & No Match & 0.12 & 0.18 & - \\
\hline 36 & 14.261 & 1138 & Fenchol & - & - & 0.03 \\
\hline 37 & 15.224 & 1131 & trans-Pinocarveol & - & - & 0.33 \\
\hline 38 & 15.492 & 1136 & cis-Verbenol & - & - & 0.07 \\
\hline
\end{tabular}




\begin{tabular}{|c|c|c|c|c|c|c|}
\hline 39 & 15.551 & 1110 & 4-Oxoisophorone & - & 0.51 & - \\
\hline 40 & 15.639 & - & No Match & 0.09 & 0.59 & - \\
\hline 41 & 16.538 & - & No Match & - & 0.35 & - \\
\hline 42 & 16.603 & 1138 & endo-Borneol & 0.10 & 1.32 & 0.25 \\
\hline 43 & 16.824 & 1109 & Isopinocamphone & - & - & 0.12 \\
\hline 44 & 17.036 & 1137 & L-Terpinen-4-ol & 0.31 & 0.75 & 0.32 \\
\hline 45 & 17.170 & - & No Match & - & 0.32 & - \\
\hline 46 & 17.443 & 1191 & Myrtenol & 0.09 & - & 0.08 \\
\hline 47 & 17.48 & 1197 & p-Cymen-8-ol & - & 0.66 & - \\
\hline 48 & 17.671 & 1143 & $\alpha$-Terpineol & 0.88 & 2.06 & 1.84 \\
\hline 49 & 17.847 & 1172 & Estragole & 1.18 & - & - \\
\hline 50 & 17.895 & 1186 & Safranal & - & 3.14 & - \\
\hline 51 & 18.166 & - & No Match & - & 0.05 & - \\
\hline 52 & 18.251 & 1119 & Verbenone & 0.21 & 2.05 & 0.14 \\
\hline 53 & 18.49 & - & No Match & - & 0.27 & - \\
\hline 54 & 18.769 & 1204 & $\beta$-Cyclocitral & - & 1.04 & - \\
\hline 55 & 18.874 & 1206 & cis-Carveol & 0.02 & - & - \\
\hline 56 & 18.932 & 1230 & $\begin{array}{l}\text { 6,6-Dimethylcycloocta- } \\
\text { 2,4-dienone }\end{array}$ & - & 0.55 & - \\
\hline 57 & 19.176 & - & No Match & - & 0.69 & - \\
\hline 58 & 19.647 & 1212 & Pulegone & 0.10 & 0.82 & - \\
\hline 59 & 20.024 & 1190 & Carvone & 0.13 & - & - \\
\hline 60 & 20.205 & 1212 & $\alpha$-Ionene & - & 0.23 & - \\
\hline 61 & 20.801 & 1212 & 2-Decenal & - & - & 0.43 \\
\hline 62 & 21.009 & - & No Match & - & 0.09 & - \\
\hline 63 & 21.350 & 1487 & $\begin{array}{l}\text { 1-Methyl-9-(1- } \\
\text { methylethylidene)bicycl } \\
\text { o[3.3.1]nonan-2-one }\end{array}$ & - & 0.39 & - \\
\hline 64 & 21.583 & 1277 & Bornyl acetate & $2-$ & - & 0.60 \\
\hline 65 & 22.177 & 1262 & Thymol & 0.15 & - & - \\
\hline 66 & 22.585 & 1262 & Carvacrol & 0.03 & - & - \\
\hline 67 & 22.764 & 1286 & Undecanal & 3 & - & 0,11 \\
\hline 68 & 23.376 & - & No Match & - & 0.22 & - \\
\hline 69 & 23.486 & 1339 & Sativene & 0.05 & 0.91 & - \\
\hline 70 & 25.459 & 1221 & $\alpha$-Copaene & 0.10 & - & 0.05 \\
\hline 71 & 24.672 & 1396 & Dehydro-ar-ionene & - & 0.93 & - \\
\hline 72 & 25.167 & 1221 & Ylangene & 0.54 & - & 0.16 \\
\hline 73 & 25.459 & 1344 & $\alpha$-Cubebene & 4.09 & 0.26 & 1.52 \\
\hline 74 & 25.814 & 1398 & $\alpha$-Cedrene & 0.04 & - & - \\
\hline 75 & 26.359 & 1474 & $\alpha$-Chamigrene & 0.08 & - & - \\
\hline 76 & 26.443 & 1410 & $\begin{array}{l}\text { 3-(2,6,6-Trimethyl-1- } \\
\text { cyclohexen-1-yl)-2- } \\
\text { propenal }\end{array}$ & - & 3.36 & - \\
\hline 77 & 26.559 & - & No Match & 0.05 & - & - \\
\hline 78 & 27.078 & 1402 & Lauraldehyde & - & - & 0.42 \\
\hline 79 & 27.273 & 1494 & $\beta$-Caryophyllene & 1.21 & 0.21 & 1.35 \\
\hline 80 & 27.397 & - & No Match & 0.13 & - & - \\
\hline 81 & 27.487 & 1398 & Cedr-8(15)-ene & 0.25 & - & - \\
\hline
\end{tabular}




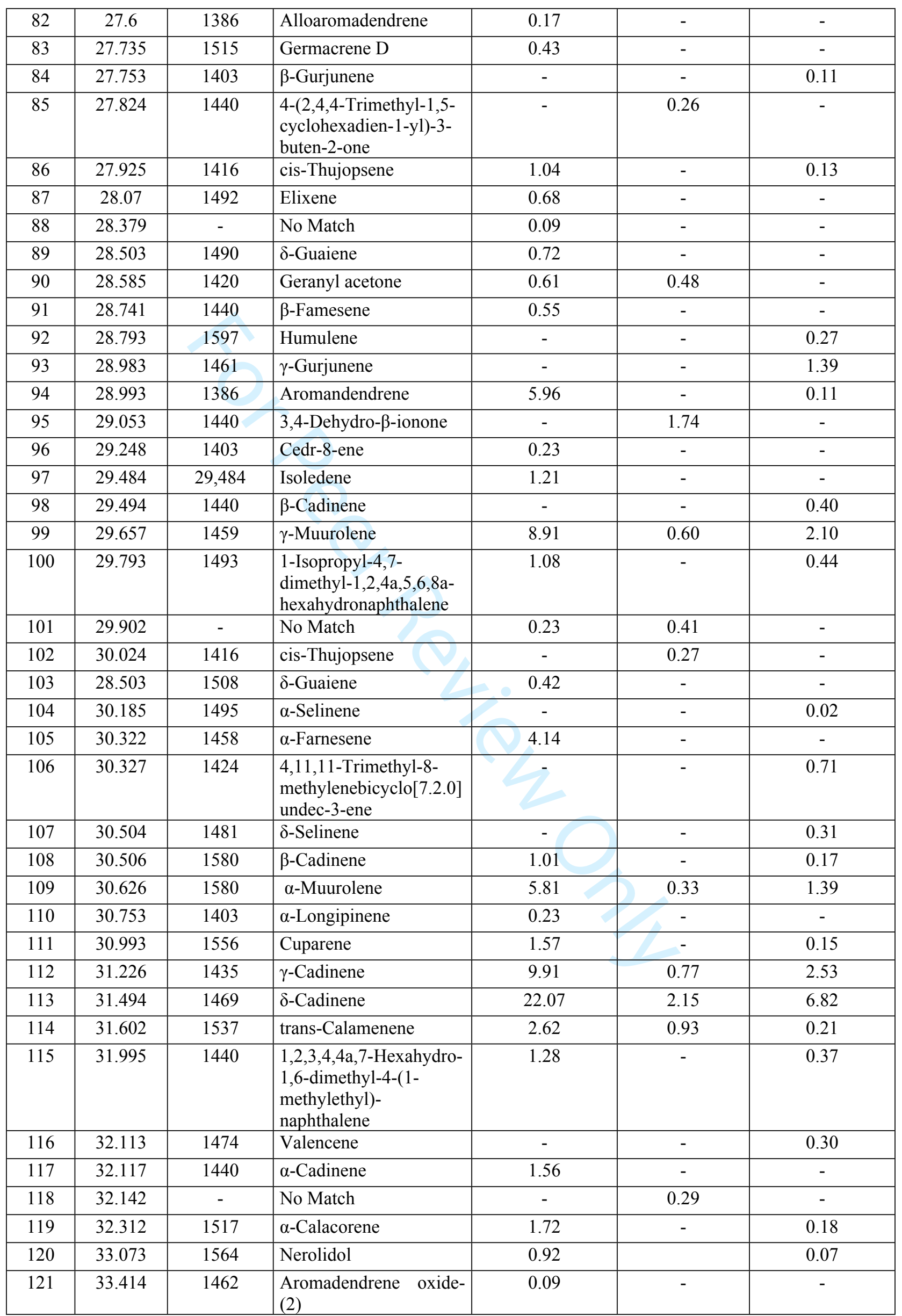




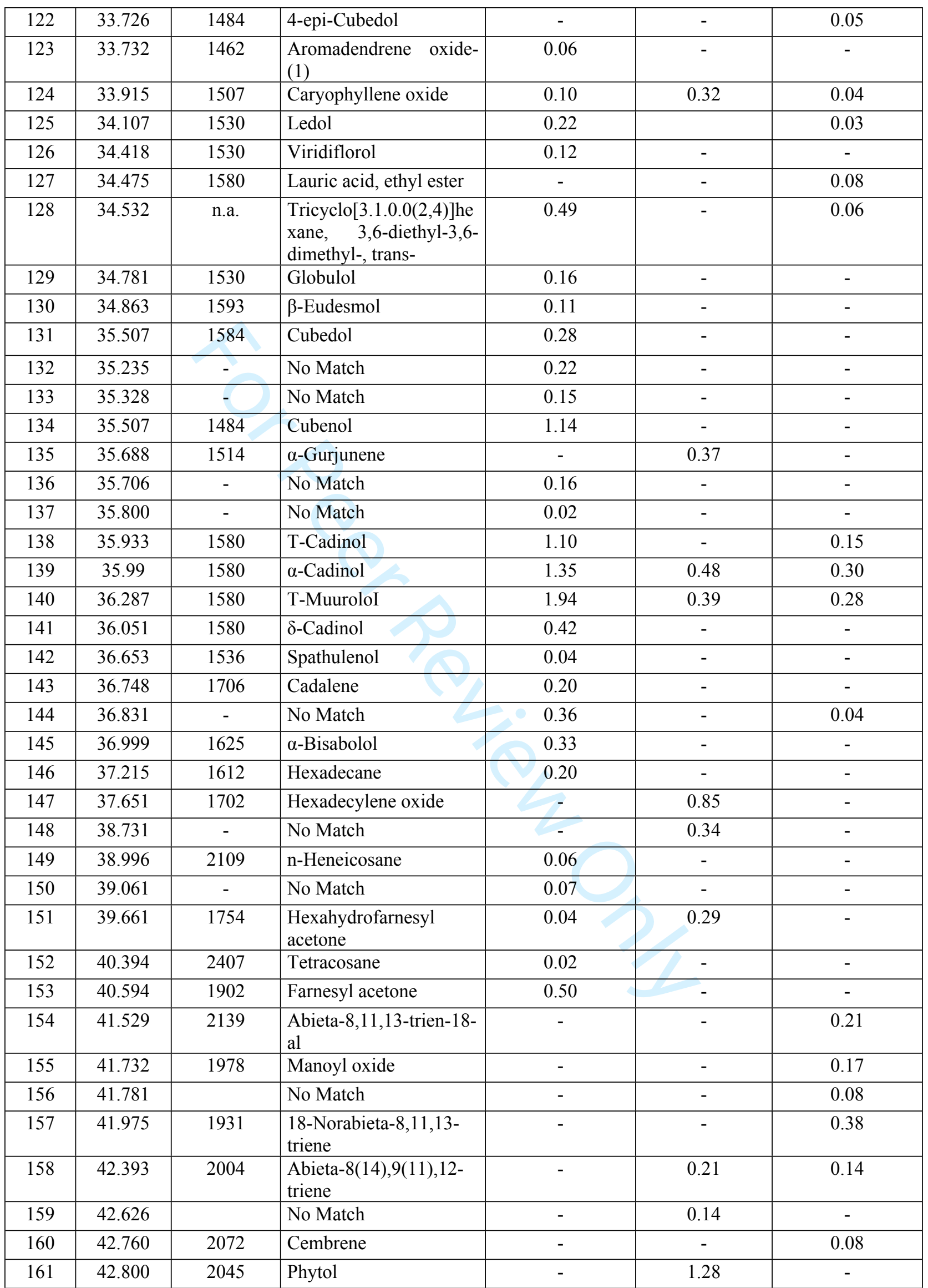


133 Fig. S1. GC-MS chromatographic profile of $R$. typhina L. hydroalcoholic extracts pf (A) 134 branches, (B) leaves and (C) fruits. Main peaks are numbered according to assignments in Table $135 \mathrm{~S} 1$
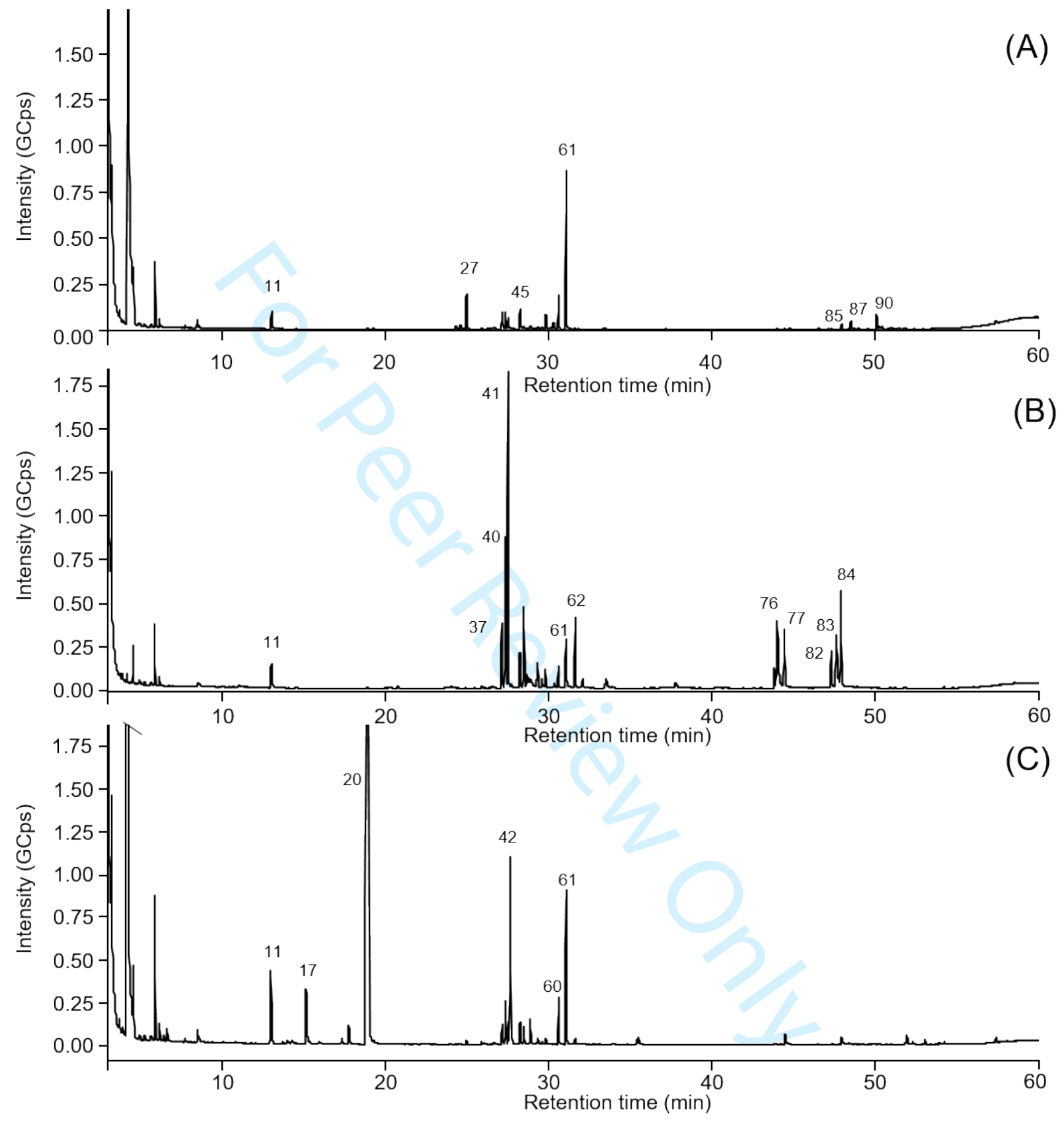
137 Fig. S2. GC-MS chromatographic profile of R. typhina L. (A) branches, (B) leaves and (C) fruits 138 EOs. Main peaks are numbered according to assignments in Table S2.
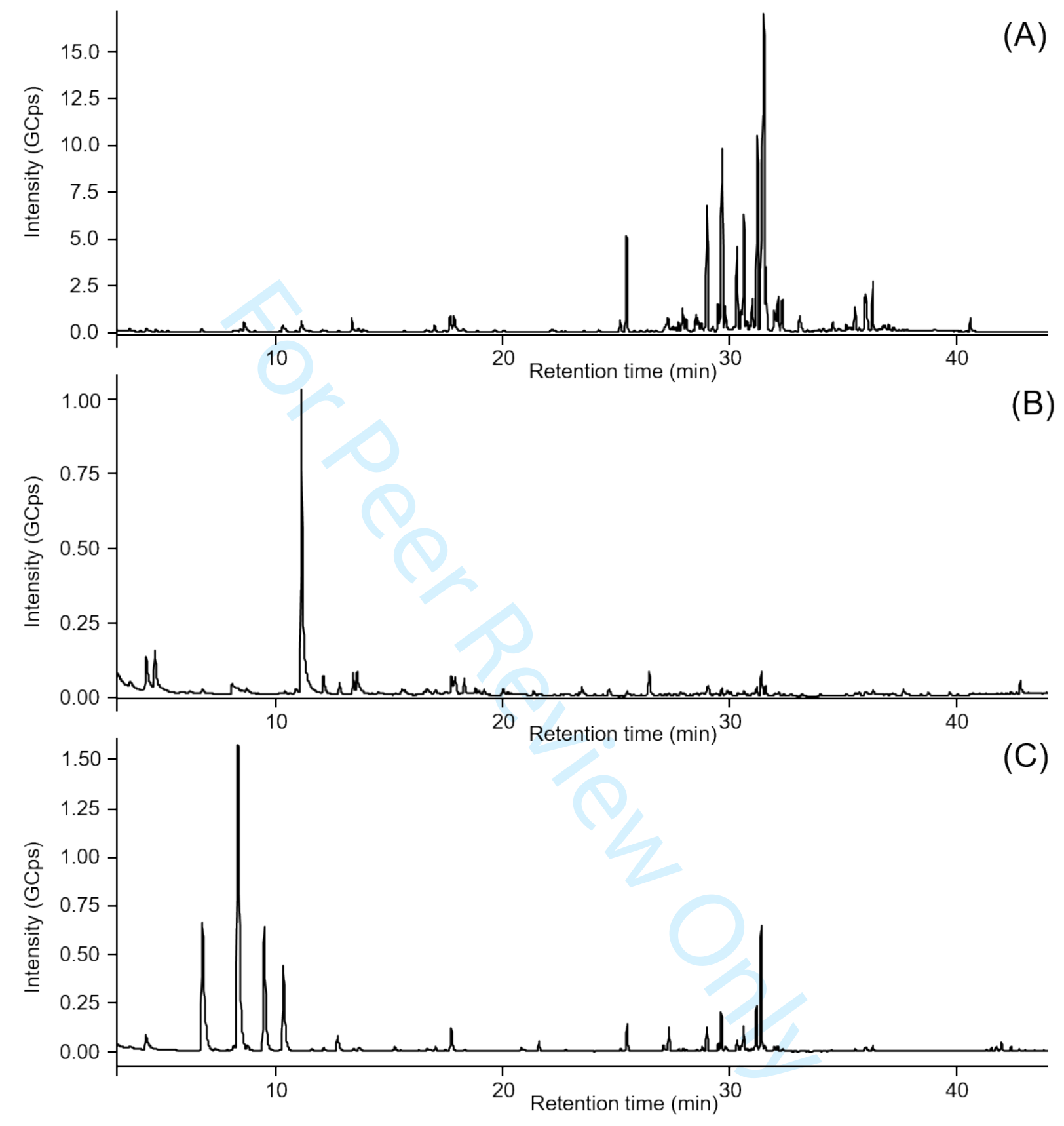